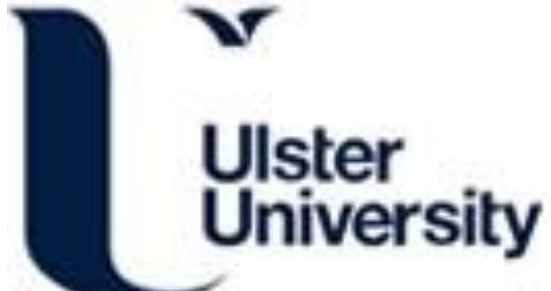

\section{Impact of sitting time on seat-interface pressure and on pressure mapping with multiple sclerosis patients}

Crawford, SA., Stinson, M., Walsh, D., \& Porter-Armstrong, A. (2005). Impact of sitting time on seat-interface pressure and on pressure mapping with multiple sclerosis patients. Archives of Physical Medicine and Rehabilitation, 86(6), 1221-1225. https://doi.org/10.1016/j.apmr.2004.08.010

Link to publication record in Ulster University Research Portal

\section{Published in:}

Archives of Physical Medicine and Rehabilitation

Publication Status:

Published (in print/issue): 01/06/2005

DOI:

10.1016/j.apmr.2004.08.010

\section{Document Version}

Publisher's PDF, also known as Version of record

\section{General rights}

Copyright for the publications made accessible via Ulster University's Research Portal is retained by the author(s) and / or other copyright owners and it is a condition of accessing these publications that users recognise and abide by the legal requirements associated with these rights.

\section{Take down policy}

The Research Portal is Ulster University's institutional repository that provides access to Ulster's research outputs. Every effort has been made to ensure that content in the Research Portal does not infringe any person's rights, or applicable UK laws. If you discover content in the Research Portal that you believe breaches copyright or violates any law, please contact pure-support@ulster.ac.uk. 


\title{
Impact of Sitting Time on Seat-Interface Pressure and on Pressure Mapping With Multiple Sclerosis Patients
}

\author{
Shelley A. Crawford, BSc, May D. Stinson, PhD, Deirdre M. Walsh, DPhil, Alison P. Porter-Armstrong, DPhil
}

ABSTRACT. Crawford SA, Stinson MD, Walsh DM, Porter-Armstrong AP. Impact of sitting time on seat-interface pressure and on pressure mapping with multiple sclerosis patients. Arch Phys Med Rehabil 2005;86:1221-5.

Objective: To examine changes in seat-interface pressure with multiple sclerosis (MS) patients.

Design: Case series.

Setting: Multiple Sclerosis Society's Resource Centre and community.

Participants: Convenience sample of 15 MS wheelchair users and 12 MS non-wheelchair users.

Intervention: Interface pressure was measured for $8 \mathrm{~min}$ utes using the Force Sensing Array pressure mapping system.

Main Outcome Measures: Number of activated sensors, standard deviation, average and maximum pressures.

Results: With the wheelchair users, significant decreases were found in the standard deviation and average and maximum pressures during 0 to 2 minutes of sitting $(P<.01)$. Average pressure was the only parameter to show a significant decrease in the non-wheelchair users $(P<.01)$ during 0 to 2 minutes. Significant increases were found in all output parameters during 2 to 4 minutes with both groups $(P<.05)$. Nonwheelchair users showed no significant changes in the output parameters after 4 minutes, but wheelchair users showed significant continued increases in the output parameters from 4 to 8 minutes $(P<.05)$.

Conclusions: Because no significant changes in interface pressure occurred after 4 minutes of sitting with the nonwheelchair users, 4 minutes may be a reasonable sitting time before interface pressure is recorded with this group. Significant changes in interface pressure continued up to 8 minutes with the wheelchair users, therefore 8 minutes or beyond may be a reasonable sitting time before recording with this group.

Key Words: Multiple sclerosis; Pressure ulcers; Rehabilitation; Technology, medical.

(C) 2005 by American Congress of Rehabilitation Medicine and the American Academy of Physical Medicine and Rehabilitation

From the Health \& Rehabilitation Sciences Research Institute, University of Ulster at Jordanstown, Newtownabbey, Northern Ireland.

Preliminary findings were presented to the Rehabilitation Engineering \& Assistive Technology Society of North America, June 2003, Atlanta, GA.

Supported by the Department of Employment and Learning (Northern Ireland) and the University of Ulster.

No commercial party having a direct financial interest in the results of the research supporting this article has or will confer a benefit on the author(s) or on any organization with which the author(s) is/are associated.

Reprint requests to Alison Porter-Armstrong, DPhil, Health \& Rehabilitation Sciences Research Institute, University of Ulster, Shore Rd, Newtownabbey, Co. Antrim, Northern Ireland, BT37 0QB, e-mail: a.porter@ulster.ac.uk.

0003-9993/05/8606-9310\$30.00/0

doi:10.1016/j.apmr.2004.08.010
$\mathbf{M}$ ULTIPLE SCLEROSIS (MS) is the most common cause of neurologic disability among young adults in the western world. ${ }^{1}$ There are about 87,000 MS patients in the United Kingdom, with Northern Ireland having a particularly high prevalence of about 3500 patients. ${ }^{2,3}$ Common symptoms of MS include decreased sensation, incontinence, and decreased vascular reactivity. All are known risk factors for developing pressure ulcers, which can be a secondary complication of MS. ${ }^{4}$ Further, because of decreased mobility, patients with MS spend long periods of time seated. When seated, one's body weight is distributed over a small surface area, which produces high interface pressures ${ }^{5,6}$ that are the principal extrinsic risk factor associated with pressure ulcers. ${ }^{7}$ Pressure mapping systems are being increasingly accepted in clinical practice because they can objectively measure interface pressure. ${ }^{8,9}$ The Force Sensing Array (FSA) pressure-mapping system ${ }^{\mathrm{a}}$ was used in this study because it has been reported to be user friendly. ${ }^{10,11}$ However, there is no consensus among researchers about the usefulness of pressure mapping output parameters.

Maximum pressure (the highest individual sensor value) has been considered a useful output parameter and is the one most commonly reported. ${ }^{12,13}$ However, it has limitations because it is sensitive to random experimental errors. ${ }^{14}$ Further, Sprigle et $\mathrm{al}^{15}$ stated that maximum pressure was not a stable value and therefore excluded it from their analysis. They advocated reporting the standard deviation (SD), which provides insight into the extent of pressure distribution. They also supported analyzing average pressure (the mean of all the sensor values) because this is considered a stable measurement. However, the average pressure value on a sensor array may not indicate the pressure peaks over bony prominences. The International Standards Organization is devising new support surface performance indices with which to evaluate wheelchair cushions ${ }^{16}$ in an attempt to overcome the limitations of currently reported pressure-mapping output parameters.

A review of relevant research articles indicates that there is limited use of the parameter that reports the number of active sensors on the pressure-sensing mat. This parameter can provide insight into the extent of contact of the thighs and buttocks with the seating surface. Distribution of weight can be determined by examining the number of activated sensors on the mat, ${ }^{17}$ thus permitting decisions about a support surface's performance. $^{14}$

Therefore, our purpose in this pilot study was to examine changes in seat-interface pressure in the MS population using 4 output parameters from the FSA pressure-mapping system: $\mathrm{SD}$, average pressure, maximum pressure, and the number of activated sensors on the pressure-sensing mat.

\section{METHODS}

\section{Study Design and Sample}

This study was designed as a case series; it was approved by the University of Ulster's Research Ethical Committee. Participants were recruited from the Multiple Sclerosis Society's Resource Centre in Belfast (Northern Ireland). The study used 
Table 1: Participants' Characteristics

\begin{tabular}{|c|c|c|c|c|}
\hline \multirow[b]{2}{*}{ Characteristics } & \multicolumn{2}{|c|}{ Wheelchair Users (Group A) $(n=15)$} & \multicolumn{2}{|c|}{ Non-Wheelchair Users (Group B) $(n=12)$} \\
\hline & Range & Mean $\pm S D$ & Range & Mean \pm SD \\
\hline Age (y) & $41.00-79.00$ & $58.55 \pm 10.74$ & $40.00-72.00$ & $53.51 \pm 9.35$ \\
\hline Weight (kg) & $38.18-82.73$ & $66.91 \pm 12.99$ & $60.45-101.82$ & $71.17 \pm 11.13$ \\
\hline Height $(\mathrm{cm})$ & $148.75-170.00$ & $157.92 \pm 7.05$ & $150.00-181.25$ & $163.13 \pm 10.05$ \\
\hline Body mass index $\left(\mathrm{kg} / \mathrm{m}^{2}\right)$ & $14.02-36.16$ & $26.96 \pm 5.53$ & $24.22-31.72$ & $26.69 \pm 2.71$ \\
\hline Years with MS & $4.00-30.00$ & $18.67 \pm 7.96$ & $0.60-23.00$ & $9.88 \pm 8.56$ \\
\hline Daily sitting time (h) & $9.00-20.00$ & $13.40 \pm 2.56$ & $10.00-15.50$ & $12.42 \pm 1.86$ \\
\hline
\end{tabular}

a convenience sample $(\mathrm{N}=27)$ that was split into 2 groups to represent variations in mobility within the MS population, because reduced mobility is a known risk factor for pressure ulcer development. ${ }^{18,19}$

Group A $(n=15)$ included 13 women and 2 men who used wheelchairs. Group B $(n=12)$ comprised 5 women and 7 men who were non-wheelchair users. All participants were 18 years of age or older and could communicate verbally. Written consent was obtained from the participants, who were informed that they could withdraw from the study at any stage for any reason, or if they experienced pain or discomfort during assessment. Further information on participants' characteristics is provided in table 1 .

\section{Instrumentation}

We used the FSA ${ }^{\mathrm{a}}$ pressure-mapping system to measure contact pressure at the buttock-seat interface. The system comprises a pressure-sensing mat that contains 256 sensors; this was connected to the FSA computer software via an interface module (fig 1). Data were recorded as color-coded maps of pressure distribution, 3-dimensional grids, and numeric output parameters. The FSA system was calibrated with an autocalibrator specific to the system and according to the instructions in the manufacturer's manual. After autocalibration, the software and a foot pump were used to check the accuracy of the sensors in $40-\mathrm{mmHg}$ intervals, up to the maximum pressure of $200 \mathrm{mmHg}$. The system was calibrated in the pressure-mapping laboratory before each assessment to ensure consistency.

\section{Procedure}

All participants were placed in an upright sitting position, with hips, knees, and ankles flexed to $90^{\circ}$ where possible. This

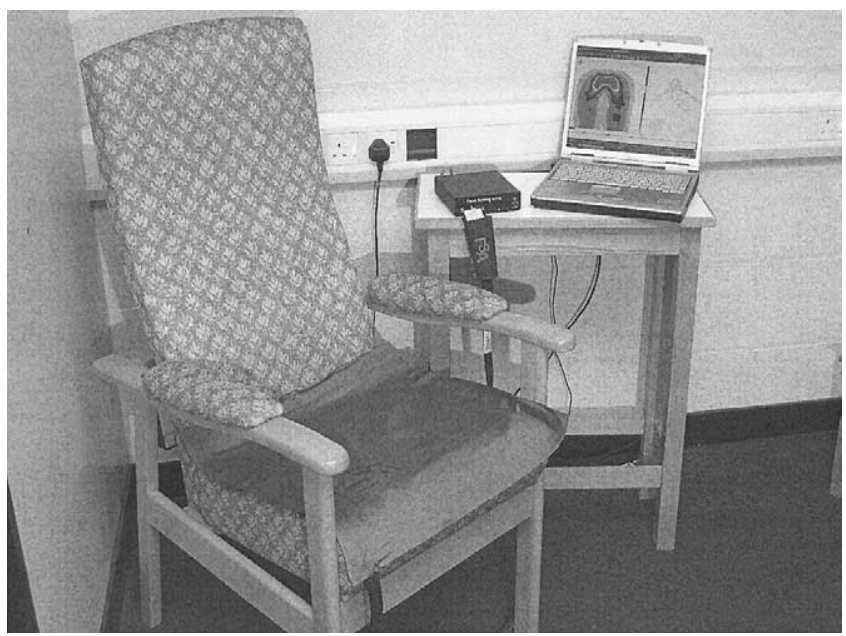

Fig 1. The FSA pressure-mapping system. sitting position is often referred to as "normal" because it allows optimal weight distribution. ${ }^{20}$ Arms were placed on the thighs to eliminate the possibility that different heights of cushions would cause relative armrest height differences. This could have subsequently influenced the results: $5 \%$ to $10 \%$ of the body weight is distributed through the armrests. ${ }^{21}$ Nineteen percent of the body weight is distributed through the feet, ${ }^{20}$ and we took care to support our subjects' feet at $90^{\circ}$ to minimize the influence of this factor on the results. Feet were supported with wheelchair footplates or blocks for group A subjects and feet were placed flat on the floor or supported with blocks if necessary for group B subjects.

Participants from group B were assessed in their own homes on the chairs they most commonly sat on to approximate standard clinical cushion evaluation procedures. ${ }^{22}$ Subjects from group A were assessed in the Multiple Sclerosis Society's Resource Centre in their own wheelchairs, the surface they most commonly sat on. Participants were assessed on their current seating surface and on each of the 6 cushions (table 2) preselected to represent varying compositions and risk levels. All of the cushions are commercially available and were newly purchased for this study.

Average and maximum pressures, SD (all interface pressure measurements), and the number of activated sensors on the mat were recorded at 2-minute intervals up to a maximum of 8 minutes. The method of having the participants sit for $8 \mathrm{~min}$ utes on each surface before recording the interface pressure was based on the results of a study by Stinson et al. ${ }^{23}$ Although Stinson found that 6 minutes was the optimal prerecording sitting time $(P<.05)$, the increase between 6 and 8 minutes bordered on statistical significance $(P=.05)$. Further, the Stinson study was conducted with healthy volunteers in a laboratory setting, under controlled conditions. We used 8 minutes for our study because our MS patients were likely to be at greater risk of pressure ulcer development.

\section{Data Analysis}

Changes in the 4 output parameters were analyzed at 4 time intervals $(0-2 \mathrm{~min}, 2-4 \mathrm{~min}, 4-6 \mathrm{~min}, 6-8 \mathrm{~min})$ for each of the 7 surfaces assessed. All data from both groups were entered into SPSS. ${ }^{\text {b }}$ All data were normally distributed and 2-way repeated-measures analysis of variance (ANOVA) was used to determine the main interactive effects between the variables and to examine changes in the 4 output parameters over time.

\section{RESULTS}

The ANOVAs showed that there were no statistically significant interactive effects between the 7 seating surfaces and the changes in the output parameters over 8 minutes for both groups. Two-way repeated-measures ANOVA also showed the effects of time on the output parameters for both groups (tables $3,4)$. A Bonferroni adjustment was applied to account for the 
Table 2: Description of 6 Preselected Cushions

\begin{tabular}{llll}
\hline \multicolumn{1}{c}{ Name } & \multicolumn{1}{c}{ Manufacturer } & \multicolumn{1}{c}{ Composition } & Manufacturer's Recommended Risk Level \\
\hline Comflex & Tools for Living (N Ireland) & Viscoelastic foam & High \\
Pudgee & Qbitus (England) & Foam and gel & Medium high \\
Flotech Plus & Medical Support Systems (Wales) & Foam base and gel sack & High \\
Orthodocs Regular & Orthodocs Limited (N Ireland) & Polyester fibers & Unknown \\
Propad & Medical Support Systems (Wales) & Foam & Medium \\
Vicair Twin 10 & Assendelft (Netherlands) & Air filled & High \\
\hline
\end{tabular}

use of multiple significance tests in the repeated-measures ANOVA. ${ }^{24}$

\section{Zero to 2-Minute Time Interval}

In the wheelchair users group during 0 to 2 minutes of sitting, there were statistically significant decreases in the SD value and in average and maximum pressures $(P<.01)$. In the non-wheelchair users group, there was a trend for the SD value and the average and maximum pressures to decrease; however, the decrease in average pressure was the only parameter that was statistically significant $(P<.01)$. There were no statistically significant changes in the number of activated sensors for either group during the first 2 minutes of sitting (see tables 3,4 ).

\section{Two to 4-Minute Time Interval}

There were significant increases in the 4 output parameters for the wheelchair users group $(P<.001)$ and for the nonwheelchair users group during 2 to 4 minutes of sitting $(P<.05)$ (see tables 3, 4).

\section{Four to 6-Minute Time Interval}

In the wheelchair users group, statistically significant increases continued in the number of activated sensors and in average and maximum pressure $(P<.05)$. However, in the non-wheelchair users group, there were no statistically significant changes in any of the output parameters (see tables 3,4).

\section{Six to 8-Minute Time Interval}

There were statistically significant increases for all the output parameters during 6 to 8 minutes in the wheelchair users $(P<.05)$. No statistically significant changes in the output parameters were noted for the non-wheelchair users (see tables $3,4)$.

\section{DISCUSSION}

Our purpose in this pilot study was to examine changes in seat-interface pressure using pressure-mapping technology with MS patients. We found no statistically significant interactive effect between the 7 seating surfaces and the time subjects spent sitting on them. This suggests that, despite our testing of a variety of cushions, the changes in interface pressure over time for the 4 output parameters were not significantly influenced by cushion type. In short, trends in interface pressure over time were similar on all cushions tested. However, to further validate this finding, future research should include cushions from different manufacturers.

\section{Zero to 2 Minutes}

There was a trend for the SD value to decrease in the non-wheelchair users group during 0 to 2 minutes of sitting, although this was not statistically significant. However, there were significant decreases in the SD value for the wheelchair users group. A smaller SD value signals a more uniform pressure profile, a desirable feature for a disabled patient's seating surface. ${ }^{15} \mathrm{~A}$ uniform pressure profile is created when the pressure-reducing cushion redistributes the pressure across a larger surface area; this is thought to show that the cushion is contouring to the shape of the patient's body. ${ }^{25,26}$ When contouring occurs, pressure is redistributed away from the bony prominence of the buttocks to the surrounding tissue, ${ }^{27}$ thereby reducing interface pressure. This process is often referred to as "envelopment" and may account for the significant decreases in average and maximum pressure values for wheelchair users and the significant decreases in average pressure for the nonwheelchair users.

\section{Two to 4 Minutes}

In contrast, significant increases in all output parameters were found for both groups during 2 to 4 minutes of sitting. The significant increases in the number of activated sensors on the mat may suggest that the extent of contact between the buttocks and thighs and the seating surface was increasing. Therefore, the patient's weight was being distributed over a larger surface area, suggesting that envelopment may still be occurring.

Despite this, the significant increases in SD indicated that there was greater dispersion among pressure values and that a less uniform pressure profile was emerging. ${ }^{23}$ A less uniform

Table 3: Two-Way Repeated-Measures ANOVA Showing the Significant Effects of Time on the Number of Activated Sensors and SD

\begin{tabular}{|c|c|c|c|c|c|c|c|c|c|c|c|c|c|c|c|c|c|c|c|c|}
\hline \multirow[b]{3}{*}{ Minutes } & \multicolumn{10}{|c|}{ No. of Activated Sensors } & \multicolumn{10}{|c|}{ SD } \\
\hline & \multicolumn{5}{|c|}{ Wheelchair Users } & \multicolumn{5}{|c|}{ Non-Wheelchair Users } & \multicolumn{5}{|c|}{ Wheelchair Users } & \multicolumn{5}{|c|}{ Non-Wheelchair Users } \\
\hline & $d f$ & $\mathrm{~F}$ & $P$ & $\begin{array}{l}\text { Increase/ } \\
\text { Decrease }\end{array}$ & $\begin{array}{c}\text { Sig } \\
\text { Level }^{*}\end{array}$ & $d f$ & $\mathrm{~F}$ & $P$ & $\begin{array}{l}\text { Increase/ } \\
\text { Decrease }\end{array}$ & $\begin{array}{c}\text { Sig } \\
\text { Level }^{*}\end{array}$ & $d f$ & $\mathrm{~F}$ & $P$ & $\begin{array}{l}\text { Increase/ } \\
\text { Decrease }\end{array}$ & $\begin{array}{c}\text { Sig } \\
\text { Level }^{*}\end{array}$ & $d f$ & $\mathrm{~F}$ & $P$ & $\begin{array}{l}\text { Increase/ } \\
\text { Decrease }\end{array}$ & $\begin{array}{c}\text { Sig } \\
\text { Level* }\end{array}$ \\
\hline $0-2$ & 1 & 6.91 & .020 & Decrease & NS & 1 & 3.63 & .830 & Decrease & NS & 1 & 14.24 & .002 & Decrease & $<.01$ & 1 & 8.40 & .015 & Decrease & NS \\
\hline $2-4$ & 1 & 54.96 & $<.001$ & Increase & $<.001$ & 1 & 42.20 & $<.001$ & Increase & $<.001$ & 1 & 53.77 & $<.001$ & Increase & $<.001$ & 1 & 17.32 & .002 & Increase & $<.01$ \\
\hline $4-6$ & 1 & 9.95 & .007 & Increase & $<.05$ & 1 & 2.67 & .130 & Increase & NS & 1 & 5.55 & .340 & Increase & NS & 1 & 0.51 & .491 & Increase & NS \\
\hline $6-8$ & 1 & 28.47 & $<.001$ & Increase & $<.001$ & 1 & 1.63 & .229 & Increase & NS & 1 & 10.77 & .005 & Increase & $<.05$ & 1 & 4.45 & .059 & Increase & NS \\
\hline
\end{tabular}

Abbreviations: NS, not significant (after correction for multiple comparisons); Sig, significance.

*The significance level after Bonferroni adjustment. The adjustment alters the original significance level to account for the increased likelihood of finding false significant results on performance of multiple tests. 
Table 4: Two-Way Repeated-Measures ANOVA Showing the Significant Effects of Time on Average and Maximum Pressures

\begin{tabular}{|c|c|c|c|c|c|c|c|c|c|c|c|c|c|c|c|c|c|c|c|c|}
\hline \multirow[b]{3}{*}{ Minutes } & \multicolumn{10}{|c|}{ Average Pressure } & \multicolumn{10}{|c|}{ Maximum Pressure } \\
\hline & \multicolumn{5}{|c|}{ Wheelchair Users } & \multicolumn{5}{|c|}{ Non-Wheelchair Users } & \multicolumn{5}{|c|}{ Wheelchair Users } & \multicolumn{5}{|c|}{ Non-Wheelchair Users } \\
\hline & $d f$ & $\mathrm{~F}$ & $P$ & $\begin{array}{l}\text { Increase/ } \\
\text { Decrease }\end{array}$ & $\begin{array}{c}\text { Sig } \\
\text { Level }^{*}\end{array}$ & $d f$ & $\mathrm{~F}$ & $P$ & $\begin{array}{l}\text { Increase/ } \\
\text { Decrease }\end{array}$ & $\begin{array}{c}\text { Sig } \\
\text { Level }\end{array}$ & $d f$ & $\mathrm{~F}$ & $P$ & $\begin{array}{l}\text { Increase/ } \\
\text { Decrease }\end{array}$ & $\begin{array}{c}\text { Sig } \\
\text { Level }^{*}\end{array}$ & $d f$ & $\mathrm{~F}$ & $P$ & $\begin{array}{l}\text { Increase/ } \\
\text { Decrease }\end{array}$ & $\begin{array}{c}\text { Sig } \\
\text { Level* }\end{array}$ \\
\hline $0-2$ & 1 & 18.94 & .001 & Decrease & $<.01$ & 1 & 22.90 & .001 & Decrease & $<.01$ & 1 & 17.51 & .001 & Decrease & $<.01$ & 1 & 8.05 & .016 & Decrease & NS \\
\hline $2-4$ & 1 & 88.61 & $<.001$ & Increase & $<.001$ & 1 & 14.45 & .003 & Increase & $<.05$ & 1 & 74.21 & $<.001$ & Increase & $<.001$ & 1 & 13.77 & .003 & Increase & $<.05$ \\
\hline $4-6$ & 1 & 11.23 & .005 & Increase & $<.05$ & 1 & 3.81 & .077 & Increase & NS & 1 & 37.43 & $<.001$ & Increase & $<.001$ & 1 & 0.01 & .912 & Increase & NS \\
\hline $6-8$ & 1 & 10.03 & .007 & Increase & $<.05$ & 1 & 3.76 & .079 & Increase & NS & 1 & 17.94 & .001 & Increase & $<.01$ & 1 & 7.21 & .021 & Increase & NS \\
\hline
\end{tabular}

*The significance level after Bonferroni adjustment. The adjustment alters the original significance level to account for the increased likelihood of finding false significant results on performance of multiple tests.

pressure profile may be attributed to the significant increases in average and maximum pressures that are likely to result from the effects of creep, which is the intrinsic tendency for pressure to increase over time when the load remains constant. ${ }^{28}$ Creep is a complex phenomenon and can exist within the patient's tissue. It can exist within the seating surface; for example, creep is a feature in viscoelastic foam cushions, ${ }^{13}$ one of which was included in this study, as well as within the pressuremapping sensor. The most recent reliability study ${ }^{29}$ found that the FSA sensor showed less than $2 \%$ creep over 10 minutes at $100 \mathrm{mmHg}$, which was lower than 2 other commercially available pressure-mapping systems. It is plausible that during 2 to 4 minutes of sitting, the process of envelopment is overshadowed by the process of creep.

\section{Four to 8 Minutes}

In the non-wheelchair users group, there were no statistically significant changes in the output parameters beyond 4 minutes, thus suggesting that interface pressure had stabilized. Therefore, 4 minutes may be a suitable sitting time for MS non-wheelchair users before interface pressure is recorded.

In comparison, statistically significant increases continued up until 8 minutes in the wheelchair users group, except for the SD value during 4 to 6 minutes of sitting. The continued increases in the number of activated sensors up until 8 minutes in this group may suggest that the subjects were continuing to immerse into the cushion and that envelopment was still occurring. However, the significant increases in average and maximum pressures suggest that the pressure profile continued to become less uniform. Again, this may show the ongoing effects of creep. Therefore, interface pressure had not stabilized and a reasonable sitting time before recording interface pressure with MS wheelchair users may be 8 minutes or beyond.

The differences between the changes in seat-interface pressure of the 2 groups could be influenced by the different surfaces on which the cushions were placed-that is, the patient's own armchair in the non-wheelchair users and a user's current wheelchair. It is likely that the wheelchair users would have experienced a more progressive loss of muscle bulk as a result of poorer mobility than did the non-wheelchair users. The atrophic changes in musculature around the buttocks and thighs can increase the effects of applied pressure when seat$\mathrm{ed}^{13}$; this may be why statistically significant increases in interface pressure continued up until 8 minutes with the wheelchair users.

Our results with the wheelchair users may challenge the findings of Stinson et al, ${ }^{23}$ who found that changes in average and maximum pressures were bordering on statistical significance at 8 minutes $(P=.05)$, whereas changes in average and maximum pressures in our study remained statistically significant up until 8 minutes. Several factors may account for the differences in the findings; Stinson ${ }^{23}$ included healthy volun- teers, whereas we recruited disabled patients. We preselected 6 cushions and the patients' current seating surfaces were assessed, whereas Stinson took all pressure measurements on a single armchair with no pressure-reducing cushion.

\section{Limitations}

This pilot study has several limitations. First, the sample size was small $(\mathrm{N}=27)$ and that can affect the generalizability of the results. Therefore, we recommend that the study be replicated with a larger number of disabled patients with a range of diagnoses. Second, interface pressure measurements were recorded for a maximum of 8 minutes. A study is currently underway with neurologic patients to determine if statistically significant changes in interface pressure occur beyond 8 minutes of sitting. Interface pressure measurements will be recorded over a 30 -minute period to determine a reasonable time for disabled patients to sit before interface pressure is recorded.

\section{CONCLUSIONS}

Pressure-mapping technology has shown that the process of envelopment is most evident during the first 2 minutes of sitting for MS patients. This study has also highlighted some interesting trends in interface pressure changes over time. During 2 to 4 minutes of sitting, the increases in the SD and average and maximum pressure highlighted the effects of creep, which may overshadow the process of envelopment during 2 to 4 minutes of sitting. Interface pressure measurements stabilized at 4 minutes of sitting for the non-wheelchair users, suggesting this may be a reasonable sitting time before recording interface pressure for this group. In contrast, with the wheelchair users group, increases in interface pressure continued up until 8 minutes; therefore, a reasonable sitting time before recording interface pressure may be 8 minutes or beyond for wheelchair users. Defining a reasonable sitting time before recording measurements is vital in establishing standardized protocols in the clinical setting and ensuring interstudy comparisons for research purposes. However, because this is the first study that has examined sitting times with disabled patients, further clinical studies are necessary before these findings are adopted in clinical and research practices. This study also demonstrated that the effects of applied pressure when seated can differ among MS patients with different levels of mobility.

\section{References}

1. McDonnell GV, Hawkins SA. An assessment of the spectrum of disability and handicap in multiple sclerosis: a population based study. Mult Scler 2001;7:111-7.

2. McDonnell GV, Hawkins SA. An epidemiologic study of multiple sclerosis in Northern Ireland. Neurology 1998;50:423-8.

3. Multiple Sclerosis Society Northern Ireland 2003. Available at: http://www.mssocietyni.co.uk. Accessed September 22, 2004. 
4. Hagisawa S, Ferguson-Pell M, Herbert J. Reactive hyperemia response to pressure-induced localized ischemia in patients with multiple sclerosis. J Neurol Rehabil 1994;8:193-201.

5. Defloor T, Grypdonck MH. Sitting postures and prevention of pressure ulcers. Appl Nurs Res 1999;12:136-42.

6. Maylor ME. Debating the relative unimportance of pressurereducing equipment. Br J Nurs 2001;10(Suppl):42-50.

7. Geyer MJ, Brienza DM, Karg P, Trefler E, Kelsey S. A randomized controlled trial to evaluate pressure-reducing seat cushions for elderly wheelchair users. Adv Skin Wound Care 2001;14:12032.

8. Taylor VC. Pressure mapping clinical protocol. In: Proceedings of Canadian Seating and Mobility Conference; 1999 Sept 22-24; Toronto (ON).

9. Wolsley CJ, Hill PD. Review of interface pressure measurement to establish a protocol for their use in the assessment of patient support surfaces. J Tissue Viability 2000;10:53-7.

10. Ferguson-Pell M, Cardi MD. Prototype development and comparative evaluation of wheelchair pressure mapping systems. Assist Technol 1993;5:78-91.

11. Scott EM, Kelly PJ, Stoddard EJ, Leaper DJ. Measurement of interface pressures in the evaluation of operating theatre mattresses. J Wound Care 1999;8:437-41.

12. Shelton F, Barnett R, Meyer E. Full-body interface pressure testing as a method for performance evaluation of clinical support surfaces. Appl Ergon 1998;29:491-7.

13. Swaine ID, Bader DL. The measurement of interface pressure and its role in soft tissue breakdown. J Tissue Viability 2002;12:13247.

14. Bain D, Ferguson-Pell M, McLeod A. Evaluation of mattress using interface pressure mapping. J Wound Care 2003;12:231-5.

15. Sprigle SH, Faisant TE, Chung KC. Clinical evaluation of customcontoured cushions for the spinal cord injured. Arch Phys Med Rehabil 1990;71:655-8.

16. International Standards Organization. Wheelchair seating Part 2: test methods for devices to manage tissue integrity-seat cushions. Geneva: ISO; 2002. ISO/TC 173/SCI, N338, 2001-08-30.
17. Sparacio J. Pressure mapping: potential benefits from technology. Interdisciplinary J Rehabil 2000. Available at: http://www.medrehabnetwork.com/art-adee.cfm?artID=9014. Accessed September 22, 2004.

18. Yarkony GM. Pressure ulcers: a review. Arch Phys Med Rehabil 1994;75:908-17.

19. Rycroft-Malone J. Pressure ulcer risk assessment and prevention. London: Royal College of Nursing; 2001.

20. Collins F. Use of pressure reducing seat cushions in a community setting. Br J Community Nurs 2002;7:15-22.

21. Burns SP, Betz KL. Seating pressures with conventional and dynamic wheelchair cushions in tetraplegia. Arch Phys Med Rehabil 1999;80:566-71.

22. Shechtman O, Hanson CS, Garrett D, Dunn P. Comparing wheelchair cushions for effectiveness of pressure relief: a pilot study. Occup Ther J Res 2001;12:29-48.

23. Stinson MD, Porter AP, Eakin P. Measuring interface pressure: a laboratory-based investigation into the effects of repositioning and sitting. Am J Occup Ther 2002;56:185-90.

24. Bland JM, Altman DG. Multiple significance tests: the Bonferroni method. BMJ 1995;310:170.

25. Cowan T. Static systems for pressure relief. Prof Nurse 1998;13: 703-10.

26. Defloor T, Grypdonck MH. Do pressure relief cushions really relieve pressure? West J Nurs Res 2000;22:335-50.

27. Brienza DM, Geyer MJ. Understanding support surface technologies. Adv Skin Wound Care 2000;13:237-43.

28. Bethaves $\mathrm{T}$. Interface pressure measurement: testing and selecting sensors. J Wound Care 2002;11:325-9.

29. Nicholson G, Ferguson-Pell M, Lennon P, Bain D. Comparative evaluation of pressure mapping systems (1): bench testing results. In: Proceedings of Rehabilitation Engineering \& Assistive Technology Society of North America: 2001 June; Reno (NV). Alexandria: RESNA. p 286-8.

\section{Suppliers}

a. Vista Medical, 55 Henlow Bay, Winnipeg, MB R3Y 1G4, Canada.

b. Version 9.0; SPSS Inc, $233 \mathrm{~S}$ Wacker Dr, 11th Fl, Chicago, IL 60606. 